\title{
Algunos aspectos del universo carvalhiano sometidos a la traducción
}

\author{
MAGDALENA TOSIK
}

La traducción por su carácter multidisciplinar se sitúa entre el arte, la destreza y la ciencia. En realidad, la práctica del traductor se funda en la combinación de los tres elementos. De ahí que dos traductores nunca realizan dos versiones iguales de un mismo texto en una misma lengua meta. Este hecho documenta que la noción de la traducción se tiende a percibir sobre todo como el proceso de negociación. Umberto Eco sostiene que: "muchos de los conceptos que circulan en traductología (equivalencia, adherencia al objetivo, fidelidad o iniciativa del traductor) se inscriben, para mí, en el aparato de la negociación" (Eco 2009: 23). En su libro Decir casi lo mismo analiza el teórico italiano el proceso de la traducción en relación con la teoría del texto abierto. Sin embargo, la teoría del texto abierto de Eco apuesta que por interpretación se entiende "la actualización semántica de lo que el texto, como estrategia, quiere decir con la cooperación de su Lector Modelo" (Eco 2000: 252). Por lo cual llegamos a la conclusión de que lo esencial en la traducción del texto literario es descubrir las estructuras narrativas de las cuales consta el mecanismo del texto, ya que de este modo el lector es capaz de gozar de indeterminaciones, llamadas así por Ingarden en 1931, o de su naturaleza de la obra abierta como expusiera Eco en 1962, que le permite entrar en el texto y, en efecto, producir la imagen.

Jolanta Kozak (2009), traductora de la literatura inglesa y americana al polaco sostiene el postulado de la necesidad de acercarse al texto original para entender cómo funciona. Tal y como señala Kozak, la característica permanente del texto se manifiesta en el hecho de conservar tanto su carácter dinámico del espacio repleto de imágenes como su estructura lógica a pesar de las limitaciones que impone el horizonte conceptual de la época en la cual se lo activa (Kozak 80). El texto consta de la textura (su manifestación física), de códigos (que conllevan el sentido) y de imágenes (que son producidas en el mismo texto). Según Kozak, la textura, junto con la imagen y el sentido del texto constituyen la unión 
que a continuación uno puede imitar en el proceso de traducción (Kozak 80).

Las premisas presentadas arriba someten el proceso de traducción a los requisitos del mecanismo narrativo que, en el caso de la serie Carvalho, han sido determinados como propios de la novela negra (Colmeiro, 1994; Vázquez de Parga, 1986). En ellos, la investigación detectivesca desempeña el papel de hilo conductor y es el motivo de crítica social se convierte en el principal elemento del mismo subgénero. De ahí que se postule que el traductor perciba el análisis literario de la obra y sus requisitos genéricos como una de las herramientas que se puede usar en el proceso de negociación entre culturas, pues es así como se entiende la traducción hoy en día (Venuti, 1995).

\section{El universo carvalhiano en la traducción}

En este artículo intentamos demostrar cómo las exigencias del mecanismo narrativo que es una consecuencia de la fórmula genérica influyen o deben influir en el proceso de la traducción. Nuestro análisis está basado en la novela Los mares del Sur, la tercera obra de la serie Carvalho del autor Manuel Vázquez Montalbán que fue publicada en 1979 por la editorial Planeta, siendo además el cuarto libro de las aventuras de Pepe Carvalho, protagonista de la serie. El libro destaca por recrear entre sus páginas los rasgos de la novela negra y por determinar a la perfección, como todos los libros del ciclo Carvalho, el tiempo y el espacio. Por tanto, afirmamos que el carácter de la crónica que expone la novela complementa las técnicas narrativas del género negro.

La acción de Los mares del Sur transcurre en Barcelona, en los barrios de Sarrià-San Gervasi, Ciutat Vella, el Barrio Chino, El Raval y San Magín - barrio ficticio situado en los alrededores del municipio de l'Hospitalet. No obstante, la acción se concretiza aún más apuntando a un momento exacto, tras las elecciones de junio de 1977, ya que el propio Carvalho pregunta: “¿Por quién votó el señor Stuart Pedrell en las elecciones de junio de 1977?" (Vázquez Montalbán 2014: 44). Igualmente, podemos identificar el momento a partir de los enunciados de otros personajes como, por ejemplo, Ana Briongos, ex-amante de Stuart Pedrell, quien relata que conoció a Pedrell a fines de 1977 (Vázquez Montalbán, 159). Por otra parte, el propio Carvalho encuentra, en el piso de Pedrell situado en San Magín, algunos recortes de periódicos que han 
sido fijados en la pared sobre el Pacto de la Moncloa, en las que se puede leer noticias muertas a fines de 1977 o durante 1978 (114).

La noción de Los mares del Sur que aporta el título proporciona el motivo principal de la novela y consta de dos elementos con los cuales el autor elabora su red de referencias culturales: la huida de la vida cotidiana hacia un lugar exótico y los mares del Sur, cuya mitología se desarrolla tras el arte. Ambos elementos sirven de herramienta para interpretar la novela y trazar sus sentidos. Asimismo, como Manuel Vázquez Montalbán abiertamente pronunció su intención es sobrepasar las reglas del género negro, por eso no debe extrañarnos que las referencias culturales se convierten en un clave para solucionar el caso del asesinato.

Asimismo, la novela Los mares del Sur, como todo lo que ocurre dentro del ciclo carvalhiano, impone ciertas exigencias al lector en cuanto al nivel de conocimiento de la cultura tanto universal como local. Es interesante que con frecuencia el autor deja al lector ante la mención del nombre o el título sin comentario en cuanto a las relaciones de dicho autor a la trama de la novela, lo que parece explicable, ya que el lector de la narrativa detectivesca espera que hasta cierto punto participe o tenga la ilusión de participar en el trabajo investigativo. Igualmente, dada la intención de recrear la crónica de la España de la transición, el texto exige el conocimiento de la particularidad local cuyo papel en el mecanismo narrativo es producir imágenes que exceden la función del mero colorido local o elemento anecdótico. Parece que en este nivel predominan las palabras de la cultura que podemos considerar como realidad, culturemas, o marcadores culturales cuya característica es la intransferibilidad y se manifiesta, precisamente, a través de la confrontación de las culturas en el proceso de traducción.

El universo del ciclo carvalhiano está repleto con, entre muchas cosas, de nombres de productos locales, platos y bebidas, nombres de los políticos u organizaciones, artistas, citas a la cultura popular. Con lo efímero que es el carácter de la crónica que expone la serie, consideramos que este nivel de Los mares del Sur es problemático para el traductor, ya que este tiene que autodefinirse en el momento del encuentro intercultural. Cuando Manuel Vázquez Montalbán crea un retrato de la época con el catálogo de las referencias culturales, históricas y políticas, el traductor enfrenta el problema de que el propio hecho de reproducir el 
texto en el idioma de su cultura no activa las referencias que el texto produce en la versión original.

Además, en Los mares del Sur, ya su vez en toda la serie, se encuentran alusiones que complican el proceso de la traducción aún más por su carácter autorreferencial. Los guiños por parte del autor al lector están al alcance de aquellos que conocen el estilo del autor. Los que conocen su obra, su biografía, sus opiniones enunciadas en la multitud de los artículos, ensayos y entrevistas son capaces de entrar de pleno en el universo montalbaniano. Sin embargo, asumimos que este nivel no influye en los sentidos e imágenes que produce el texto, sino que es más bien un elemento que intensifica el placer de la lectura. No obstante, es un elemento más que debe ser considerado en el proceso de la traducción.

La lectura de Los mares del Sur requiere que el lector reconozca la abundancia de las referencias que incluye para reconstruir la red de los sentidos que la novela ofrece. Por una parte, en el caso de su traducción al polaco, el traductor debería ser responsable de activar el mecanismo que producen las referencias a la cultura española de la época de la transición teniendo en cuenta la historicidad dela novela, lo que de algún modo imposibilita la sustitución de los elementos culturales. Por otra parte, la crónica que adopta la forma de la novela negra es otro factor impactante en la estrategia traductora. Los elementos de la cultura origen deberían producir referencias a lo largo de la lectura, ya que precisamente este proceso es uno de los modos gracias al cual el texto exterioriza sus rasgos de novela detectivesca. Por este motivo, una de las funciones del traductor del ciclo carvalhiano es facilitar el acceso a este nivel de la lectura.

Ahora bien, entendemos que el reto principal en cuanto al valor cultural de la novela reside en la dificultad que conlleva escribir sobre la crónica de la época. Por lo tanto, es básicamente el carácter documental del texto el motivo que convence al traductor para revelar su presencia en las notas a pie de página o en el prólogo. Sin embargo, son varios los investigadores y traductores que comparten la opinión de que la intervención abierta del traductor es señal del fracaso en el proceso traductor. Tal y como lo comenta Newmark, el traductor no debe tener dudas en aplicar un prólogo y notas para hablar del uso y significado de los términos que emplea el autor. Sin embargo, el teórico excluye los textos que 
necesitan la ilusión artística de que el traductor no existe (Newmark, 131). De ahí que tengamos que poner énfasis una vez más en el rasgo cíclico que adopta la novela policiaca. Como ya hemos comentado, el género tiende a posibilitar al lector (aparentemente) a que participe en la investigación. Lo mismo ocurre en la serie Carvalho, donde los marcadores culturales desempeñan un papel importante en el mecanismo de la investigación al ejercer de referencia y evidencia ante los ojos del lector quien, durante el proceso de la lectura, actúa como si imitara el proceso de deducción.

Resumiendo, al traducir las referencias que se hacen de la cultura en las novelas de la serie Carvalho, el traductor enfrenta la ardua tarea que se manifiesta en el carácter del propio texto, al combinar elementos de la novela negra y la crónica. Por una parte, como la novela detectivesca demanda el papel activo del lector, el traductor tiende a ocultar su presencia para no interferir en el proceso de lectura cuyo placer viene de la participación autónoma del lector en la investigación. El lector de la novela detectivesca supone que encuentra todos los detalles dentro del texto y cada intervención exterior que ayude a investigar arruina el placer de la lectura. Por otro lado, la crónica, cuyo mecanismo narrativo está basado en crear el alto grado de la credibilidad, se caracteriza por la introducción de citas a las fuentes, notas a pie de la página y bibliografías. Por eso, la presencia de otra fuente de información concretizada en la persona del traductor parece una solución natural para acercar el texto de dicho género al lector de la versión traducida. De ahí que surja la cuestión de la presencia del traductor en las novelas de la serie Carvalho, serie que por su estructura dual impone dos estrategias antagonistas en cuanto a la forma de la intervención en el texto. A la luz de estas observaciones expondremos, a continuación, algunos de los principales aspectos del mecanismo narrativo que conducen al lector a la necesidad de realizar una interpretación cultural de la obra.

\section{La investigación literaria}

En el siguiente apartado pretendemos analizar una característica fundamental para el género de la novela detectivesca: la investigación que realiza el detective Pepe Carvalho en la tercera novela del ciclo, Los mares del Sur (1979) comparando la versión original con la traducida al polaco por Maria Raczkiewicz-Śledziewska y editada en 2004 por Noir 
sur Blanc. Observamos cómo Manuel Vázquez Montalbán activa la maquinaria del texto y conduce al lector a operar entre diferentes niveles de la lectura creando la metáfora del viaje para diversificar el valor cognitivo de la obra y realizar la investigación. En el caso de Los mares del Sur parece obvio que la metáfora está codificada en el título de la novela. Por lo tanto, resulta evidente que el lector de Los mares del Sur debería ser capaz de reconstruir la metáfora literaria de los mares del sur que atribuye más sentidos al motivo principal de la huida del hombre rico de su vida. El autor facilita el proceso, ya que el mismo detective realiza la investigación de carácter literario y las referencias que el lector necesita están expuestas y analizadas en el texto de la novela.

George Tyras mantiene que en Los mares del Sur, la investigación acerca del motivo literario expone el tema más obsesivo de la obra montalbaniana: el descubrimiento de un lugar al que no quisiéramos regresar nunca. El motivo se manifiesta en las siguientes obras de Vázquez Montalbán: el poema titulado "Nunca desayunaré en Tiffany" (en Una educación sentimental, 1967), "Movimientos sin éxito" (1969), fragmentos de Manifiesto subnormal (1970) entre los que despunta el tema tomado prestado de T.S. Eliot: "Lea hasta entrada la noche y en invierno viaje hacia el Sur", dos textos que se refieren a Paul Gauguin: poema "Gauguin" (Una educación sentimental, 1965) y ensayo posterior a Los mares "Gauguin. La larga huida" (1991) (Tyras, 2007: 111). Es la información inalcanzable al lector polaco, ya que hasta hoy tenemos traducidas al polaco solo seis novelas del ciclo Carvalho.

Sin embargo, la misma investigación literaria se realiza en las páginas de la novela tras la información que aporta el detective a lo largo de sus pesquisas. El título y el epígrafe (più nessuno mi porterà nel sud) ya sugieren el motivo principal de la obra. Luego nos enteramos de que la nota fue encontrada en el bolsillo del difunto Stuart Pedrell que es la misma línea del poema y, por consiguiente, Carvalho encuentra más fragmentos sobre el tema en el despacho de la víctima: el poema "Gauguin" del autor "cuyo nombre no le dijo nada a Carvalho", un fragmento en inglés de "La tierra baldía" de T. S. Eliot, un fragmento del poema Los mares del sur de Cesare Pavese en italiano y, por fin, también en italiano un fragmento del poema de Salvatore Quasimodo "Lamento per il Sud" incluido en el poemario La vita non è sogno (1949). Afortunadamente, al encontrar los fragmentos en el despacho de Stuart 
Pedrell es el mismo detective quien traduce mentalmente todos los fragmentos resolviendo el problema de la intervención traductora (que sería justificada, ya que el lector español es capaz de entender el mensaje general del poema italiano, en cambio no es así con el lector polaco para quien si no conoce ninguna lengua romance no es tan sencillo reconocer el sentido de las palabras en italiano). En este momento está claro que el traductor debe abstenerse de identificar los fragmentos y sus autores, ya que no lo hace el autor y consideramos que el hecho de presentarlos en la versión original es una pista para realizar la investigación o por lo menos hacerse consciente de la posibilidad de hacerla. En este fragmento el lector polaco pierde este nivel de la alusión literaria que consta de las palabras irónicas y autoreferenciales de Vázquez Montalbán quien es el propio autor del fragmento "Gauguin" citado aquí, ya que el poema no está publicado en polaco.

El motivo vinculado con la figura de Gauguin y con la huida reaparece casi cada vez cuando Carvalho descubre el nuevo espacio donde vivió Pedrell. Descubrimos que "leer hasta entrada la noche y en invierno viajar hacia el sur" es el estribillo etílico de Pedrell, que solía ver la película Soberbia (la película dirigida por Albert Lewin The Moon and Sixpence (1942), adaptación de la novela de W. Somerset Maugham (1919) inspirada en la figura de Paul Gauguin), que guardaba las tarjetas postales con las reproducciones de los cuadros de Paul Gauguin y tenía "la reproducción pintada del ¿Qué somos? ¿Adónde vamos? ¿De dónde venimos?" en su casa de Putxet1. Todos los elementos pertenecen al patrimonio cultural bien reconocido al nivel mundial y el lector puede entrar en las vías de la investigación para reconstruir el mito que lleva la figura del artista Paul Gauguin por su propia cuenta, ya que el traductor es capaz de colocar los títulos de las obras que funcionan en la cultura polaca.

La investigación llega al punto crucial en la fiesta organizada por Sergio Beser, catedrático y especialista en la literatura. En aquel momento se revelan los nombres de los poetas y Beser expone la interpretación

\footnotetext{
1 Vázquez Montalbán cambia el orden de las preguntas en el título del cuadro que son las siguientes: ¿De dónde venimos? ¿Quiénes somos? ¿Adónde vamos? En la traducción polaca, la traductora inserta la versión del cuadro correcta Skadprzybywamy? Kim jesteśmy? Dokąd idziemy? (Vázquez Montalbán, 2004: 40)
} 
del mito del sur como el paraíso de los artistas descubierto por los americanos (así podemos interpretar la presencia y el sentido del estribillo de T.S. Eliot). Sin embargo, los poetas italianos desenmascaran la visión idealista del sur. Beser comenta que:

Pavese, en el poema, habla de la fascinación que ejerce sobre un adolescente el recuerdo de un pariente marino que ha recorrido el mundo. (...) Para el muchacho los mares del Sur son el paraíso; para el marino, un paisaje marcado por el trabajo cotidiano y rutinario (Vázquez Montalbán, 2014: 100).

En el poema de "Quasimodo" el académico lo desvela citando más líneas y comenta que es un poema social, escrito en pleno neorrealismo crítico y enfatiza un contrapunto amoroso de un hombre desarraigado que desvela su tristeza a su mujer. Aparentemente, el detective y el académico llegan a la conclusión de que la investigación no aporta las pistas que facilitaran encontrar la solución de la muerte de Pedrell. No obstante, para el lector el mito literario del sur añade la nueva perspectiva para interpretar y entender la huida de Pedrell que interpretada solo con las palabras de sus familiares y amigos parece solamente un capricho del hombre inmaduro.

En la versión polaca los fragmentos de la poesía están presentados en la versión traducida por otros autores, como los son: T.S. Eliot por Czesław Miłosz, García Lorca (cuyo estribillo: aunque sepa los caminos, nunca llegaré a Córdoba sirve a Beser para poner de relieve la inutilidad de la fuga al Sur alabada por T.S. Eliot) por Janusz Strasburger y Salvatore Quasimodo por Zbigniew Bieńkowski. Lamentablemente la traductora no especifica en una nota bibliográfica nada al respecto por lo que el proceso de codificar se complica. Por suerte aparece el título en polaco del poema de Salvatore Quasimodo que en la versión española del libro aparece en italiano. La lectura del poema pudiera proporcionar la nueva perspectiva hacia la investigación literaria, ya que Salvatore Quasimodo exterioriza el tema del sur de Italia pobre y nada ideal. La imagen a la cual se refiere el poema y que es la anticipación de la representación del concepto del sur en forma de la ciudad San Magín está enfatizada con la referencia a dos canciones L'emigrant cantada por Emili Venrell y El emigrante, interpretada por Juanito Valderrama. En la versión polaca, al igual que ocurre en la versión española con las referencias a ambas canciones, se entrega con las palabras: "Es como L'emigrant de Vendrell o 
El emigrante de Juanito Valderrama" (Vázquez Montalbán, 2014: 102), en polaco: "Coś jak L'emigrant Vendrella albo Emigrant Juanita Valderramy"2 (Vázquez Montalbán, 2004: 91). La traductora traduce el título español y deja el título original de la canción catalana. Es obvio que las canciones y sus intérpretes son poco conocidos para el público lector polaco. Por lo tanto, suponemos que el traductor debiera por lo menos facilitar entender que se trata de las canciones, una catalana y otra española intercalando en el texto las palabras como "cantada por", "interpretada por" o "canción catalana" para que la referencia cultural se realiza a través de hacer correspondencia al propio ámbito. De todas formas, los títulos que son paralelos en polaco, español y catalán recuerdan y evocan el motivo de la emigración en cada uno de las tres lenguas, pero en la versión polaca sin la intervención traductora se pierde la alusión a la cultura catalana, ya que es poco probable que el lector polaco no reconozca la diferencia entre idiomas

Aunque durante la fiesta en la casa del académico los protagonistas proyectan la sensación de considerar la investigación literaria como algo inútil, el proceso continúa. Después de la borrachera encontramos al detective en su casa luchando contra la resaca y dejando su cerebro procesar las informaciones que había conseguido la misma noche. Cuando recupera la consciencia, Carvalho pregunta dónde está el sur y encuentra la respuesta: "el sur es la otra cara de la luna" (Vázquez Montalbán, 2014: 106). La frase inicia el proceso de localizar la ubicación donde había vivido Sturat Pedrell un año antes de su muerte y al mismo tiempo es la referencia al título de la novela de Juan Marsé Esta cara de la luna (1962) (Tyras, 2003: 18), idea que se le ocurre a Carvalho cuando mira la luna. La novela de Marsé relata la historia de un joven burgués barcelonés rebelado contra su familia y clase social. La conciencia social le hace establecerse en la otra cara de la luna social y le lleva al fracaso. De ahí que el autor intercale la referencia intertextual que da la luz a la figura de Stuart Pedrell y, en su vez, es imposible de captar por el lector polaco, ya que el libro de Juan Marsé no está traducido al polaco ${ }^{3}$. Como

\footnotetext{
2 Traducción de Maria Raczkiewicz-Śledziewska

3 No es la única referencia a la figura de Juan Marsé: una de los personajes que vuelve a aparecer a lo largo de la serie es Teresa Marsé cuyo nombre es la combinación del apellido del escritor y el título de su libro Últimas tardes con Teresa (1966).
} 
no es posible orientar al lector polaco para investigar el motivo de modo autónomo, la única solución de parte del traductor es explicar el método deductivo del detective que sigue con las connotaciones literarias o ignorar esta parte de la investigación de manera que la lógica de la investigación literaria se convirtiera en el efecto secundario de la borrachería y el monólogo descontrolado. En efecto, debido a la falta de la intervención de parte del traductor en la versión polaca de Los mares contamos con la última solución.

La investigación literaria se acaba con el último fragmento marcado en el tomo Poesías completas de Luis Cernuda, encontrado en el piso de Pedrell en San Magín. Esta vez el texto mismo incluye tanto el título (Las islas) y el autor del poema como el acercamiento al tema: "relataba la aventura de un hombre que llega a una isla, se lo tira una mujer" y después reflexiona sobre el recuerdo y el deseo "¿No es el recuerdo la impotencia del deseo?” (Vázquez Montalbán, 2014: 133). El texto nos proporciona toda la información para seguir con la referencia literaria que una vez más enfatiza la posible motivación de Pedrell para trasladarse a San Magín.

Ahora bien, la reconstrucción de la investigación que ejecuta el detective junto al lector en Los mares del Sur requiere considerar por parte del traductor, la posibilidad de reproducir las referencias literarias presentadas en el texto del modo que no altere los procedimientos investigativos que propone el autor. Las numerosas pistas literarias que presenta el autor desarrollan la metáfora del viaje y, a su vez, proporcionan el suspense de la investigación clásica, ya que gracias a las connotaciones literarias Carvalho encuentra la casa de Pedrell. En la versión polaca del texto, esta táctica narrativa es imposible de captar. De ahí que en el siguiente apartado cuando nos adentramos en el carácter metaliterario de la obra montalbaniana propongamos la intervención del traductor como herramienta de ayuda y apoyo del lector polaco.

\section{La metaliteratura}

Con vistas a la parte anterior de este artículo, no cabe la menor duda que Los mares del Sur es una obra representativa en cuanto a la presencia de los motivos metaliterarios de la serie, pues en ella las referencias metaliterarias son las más exigentes en cuanto a la traducción por el papel que desempeñan en el hilo conductor de la investigación. En este apartado 
demostramos otros casos de aplicar las referencias a la literatura y los problemas que surgen en torno de su traducción al polaco.

Una de las primeras escenas de Los mares que contiene el comentario metaliterario es la conferencia sobre la novela negra. La intención paródica de la escena se pone de manifiesto por la abundancia de términos literarios y precisamente es la razón, aparte de su universalidad, la que hace que la traductora se abstenga de explicarlos, ya que la confusión que provocan constituye el comentario satírico sobre las teorías literarias. Sin embargo, el error de la traductora que es la consecuencia de la traducción literal del término "la novela negra" (czarna powieść) que puede provocar problemas en cuanto a la referencia extratextual, ya que no existe en polaco dicho término. Todavía en uso, encontramos los siguientes términos: "powieść noir", "hard-boiled" y "czarny kryminał", siendo este último el equivalente literal de la novela criminal negra que contiene la referencia al color negro que uno necesita para entender el humor del comentario: "Cuando la burguesía no puede conservar el control de la novela empieza a pintarla de colores" (Vázquez Montalbán, 2014: 58).

En la misma escena, donde surge el nombre de Juan Marsé, el nombre del escritor proporciona la oportunidad de la intervención traductora quien con una nota a pie de página habría podido introducir la información imprescindible para realizar la "investigación literaria" presentada en el apartado anterior. Gracias a la información tal como: "Juan Marsé autor de las novelas Esta cara de la luna (1962), Últimas tardes con Teresa (1966)" podría orientar al lector hacia las referencias que hace el autor, imitar el proceso de la deducción gracias a la antelación con la cual se transmite los detalles sobre la obra de Juan Marsé. Asimismo, el proceso de la lectura del texto meta conseguiría las posibilidades del texto original y el traductor recuperaría por la falta de la nota a pie de página (cuya presencia de todas formas revelaría al lector la inutilidad de la investigación que realiza como persona que no pertenece a la cultura del texto original) en la escena cuando gracias a las connotaciones literarias Carvalho localiza la estancia de Stuart Pedrell.

El texto es un todo lleno de sentido, como un mecanismo que produce imágenes o referencias, por eso el traductor se ve obligado a atender todos los aspectos que son responsables de activarlas funciones referenciales e incluso extratextuales. A veces en el proceso de la traducción se 
pierde las referencias potenciales que, aunque actualmente no son posible realizar por falta de la traducción de los poemas de Vázquez Montalbán al polaco, podrán salir a la luz el día en que la poesía del autor se incluya en la base cognitiva del lector polaco. La frase: "La penumbra iluminada por el fuego acentuaba sus rasgos fundamentales de muchacha sin flor" (Vázquez Montalbán, 2014: 28) hace, en primer lugar referencia al título de la novela de Marcel Proust A la sombra de las muchachas en flor (À l'ombre des jeunes filles en fleur, 1919) que no es fácil encontrar en polaco con este título literal de la novela francesa, ya que ha sido modificada $W$ cieniu zakwitajacych dziewczat $t^{4}$ (A la sombra de las muchachas florecidas -versión polaca del título francés). Al mismo tiempo es la alusión al poema de Manuel Vázquez Montalbán A la sombra de las muchachas sin flor (1973). Por la modificación de la sintaxis del título de la obra de Marcel Proust en la cultura polaca parece difícil conservar las dos referencias a la vez, y así en la traducción de Maria Raczkiewicz-Śledziewska desaparecen ambas, por lo que la traductora rechaza la metáfora de "la muchacha sin flor" interpretándola con las siguientes palabras: "dziewczyna, która na pewnoutraciłajużdziewictwo"5 (Vázquez Montalbán, 2004: 27).

Como hemos demostrado, la necesidad de la intervención del traductor en el texto y su forma depende del carácter de la referencia y la función que desempeña en el mecanismo narrativo. Desde luego, la traducción de los elementos de cultura en los textos, cuya forma está determinada por la fórmula genérica, exige al traductor que someta sus decisiones a la reflexión e investigación necesaria acerca de las soluciones que aplique en el texto. Sin embargo, a pesar de la tendencia a ocultar la presencia del traductor en los textos del género policiaco, la fórmula no cierra las vías a la intervención traductora dentro del texto. Además, la intención del autor que se manifiesta en la alteración de la fórmula cuando el propio proceso de la investigación detectivesca se transfiere al nivel de la reflexión sobre los motivos literarios, hace preciso que el proceso de recrear el mecanismo narrativo esté basado en las referencias culturales.

\footnotetext{
$-$

4 Traducción literal: "A la sombra de las muchachas florecidas.” La traducción es nuestra 5 Traducción literal: "La muchacha que sin duda ha perdido la virginidad." La traducción es nuestra
} 
Algunos aspectos del universo carvalhiano sometidos a la traducción 57

\section{Las organizaciones y partidos políticos}

Después de observar los motivos literarios que activan al lector para realizar la táctica textual de la investigación, pasamos al análisis del motivo que contribuye a la novela el carácter de la crónica. Uno de los temas primordiales de Los mares del sur es la reflexión sobre los mecanismos políticos desde la perspectiva obrera y enmarcado en el momento histórico de la transición (estamos entre el momento de firmar los Pactos de Moncloa en 1977 y la ratificación de la Constitución en el referéndum del 6 de diciembre de 1978), por eso no debe extrañarnos que a lo largo de la lectura surjan los nombres de los partidos políticos, la mayoría en forma de siglas. Así que el nombre de los partidos políticos en el proceso de la traducción se convierte en un elemento que uno prefiere conservar para conseguir el efecto de la autenticidad.

La traductora de Los mares del Sur opta por conservar las denominaciones de los partidos políticos en la versión española para luego comentar el nombre a pie de la página. No obstante, no sabemos por cierto quién es el autor de las explicaciones, así que, como puede verse en la tabla siguiente, en la versión polaca todos los comentarios a pie de la página no tienen la autoría. Por lo tanto, podemos observar las intervenciones directas de la traductora o el redactor del texto.

LAS ORGANIZACIONES Y PARTIDOS POLÍTICOS EN LOS MARES DEL SUR

\begin{tabular}{|c|c|c|}
\hline $\begin{array}{l}\text { LAS } \\
\text { DIGLAS } \\
\text { DEL TEXTO } \\
\text { LOS MARES } \\
\text { DEL SUR DE } \\
\text { MANUEL } \\
\text { VÁZQUEZ } \\
\text { MONTALBÁN } \\
(2014) \\
\end{array}$ & $\begin{array}{l}\text { LOS COMENTARIOS EN NOTAS A } \\
\text { PIE DE LA PÁGINA DE LA VER- } \\
\text { SIÓN TRADUCIDA POR MARIA } \\
\text { RACZKIEWICZ-ŚLEDZIEWSKA } \\
(2004)\end{array}$ & $\begin{array}{l}\text { OBSERVACI- } \\
\text { ONES }\end{array}$ \\
\hline 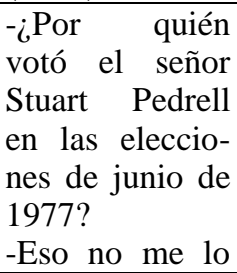 & $\begin{array}{l}\text { UCD (Unión de Centro Democrático) - } \\
\text { Unia Centrum Demokratycznego. (p. } \\
41)\end{array}$ & $\begin{array}{l}\text { El nombre del } \\
\text { partido traduci- } \\
\text { do al polaco } \\
\text { provee suficien- } \\
\text { te información } \\
\text { para entender la } \\
\text { orientación }\end{array}$ \\
\hline
\end{tabular}




\begin{tabular}{|c|c|c|}
\hline $\begin{array}{l}\text { dijo. } \\
\text {-¿Por UCD? } \\
\text {-No. No creo. } \\
\text { Algo más radi- } \\
\text { cal. } \\
\text { (p. 44) }\end{array}$ & & $\begin{array}{l}\text { política } \\
\text { partido. }\end{array}$ \\
\hline $\begin{array}{l}-i \text { Y usted? } \\
\text {-No veo el } \\
\text { interés que } \\
\text { pueda tener mi } \\
\text { voto. } \\
\text {-Disculpe. } \\
\text {-Voté a Esquer- } \\
\text { ra Republicana } \\
\text { de Catalunya, si } \\
\text { le interesa } \\
\text { saberlo. } \\
\text { (p. 45) }\end{array}$ & $\begin{array}{l}\text { Esquerra Republicana de Catalunya } \\
\text { (p.41) }\end{array}$ & $\begin{array}{l}\text { En el texto tradu- } \\
\text { cido al polaco el } \\
\text { nombre queda en } \\
\text { la versión catalana } \\
\text { sin comentarios, } \\
\text { ya que el lector } \\
\text { polaco no tiene la } \\
\text { información sobre } \\
\text { la orientación del } \\
\text { partido para en- } \\
\text { tender que Stuart } \\
\text { Pedrell y su ma- } \\
\text { yordomo votaron } \\
\text { por los partidos de } \\
\text { los extremos } \\
\text { opuestos. }\end{array}$ \\
\hline $\begin{array}{l}\text { El taxista hab- } \\
\text { laba andaluz y a } \\
\text { los dos minutos } \\
\text { de conversación } \\
\text { ya le había } \\
\text { dicho que en las } \\
\text { pasadas elecci- } \\
\text { ones generales } \\
\text { había votado } \\
\text { por los comu- } \\
\text { nistas del } \\
\text { PSUC. } \\
\text { (p. 60) }\end{array}$ & $\begin{array}{l}\text { PSUC (Partit Socialista Unificat de } \\
\text { Catalunya) - Katalońska Partia Socja- } \\
\text { listyczna. (p.55) }\end{array}$ & $\begin{array}{l}\text { El nombre del } \\
\text { partido traducido } \\
\text { al polaco combi- } \\
\text { nada con la pa- } \\
\text { labra "comu- } \\
\text { nistas" provee } \\
\text { demasiado } \\
\text { contexto para } \\
\text { entender el hu- } \\
\text { mor que presen- } \\
\text { tan las decoracio- } \\
\text { nes en el coche } \\
\text { del taxista (foto } \\
\text { de la familia fea, } \\
\text { la Virgen de } \\
\text { Montserrat, un } \\
\text { lacito de Barça y } \\
\text { la constatación } \\
\text { que el taxista } \\
\text { votó por los } \\
\text { comunistas) }\end{array}$ \\
\hline
\end{tabular}


Algunos aspectos del universo carvalhiano sometidos a la traducción 59

\begin{tabular}{|c|c|c|}
\hline $\begin{array}{l}\text { Durante la } \\
\text { guerra vinieron } \\
\text { a buscarme los } \\
\text { de la FAI y los } \\
\text { recibí con mi } \\
\text { mejor batín de } \\
\text { seda. } \\
\text { (p. 64) }\end{array}$ & $\begin{array}{l}\text { FAI (Federación Nacional Ibérica) - } \\
\text { organizacja rewolucyjna anarchistów } \\
\text { założona w } 1927 \text { roku, znana z wielu } \\
\text { spektakularnych akcji terrorystycznych. } \\
\text { (p. 59) }\end{array}$ & \begin{tabular}{lr}
\multicolumn{2}{l}{ Comentario } \\
necesario para \\
que el lector que \\
no conoce la \\
historia de \\
España entienda \\
el humor de la \\
situación cuando \\
el marqués mani- \\
fiesta su origen \\
aristocrático a \\
pesar de la \\
amenaza de ser \\
asesinado por los \\
terroristas.
\end{tabular} \\
\hline $\begin{array}{l}\text { Planas } \\
\text { presenta a las } \\
\text { elecciones de } \\
\text { la CEOE, la } \\
\text { Patronal como } \\
\text { la llama la } \\
\text { prensa. } \\
\text { (p.63) }\end{array}$ & $\begin{array}{l}\text { Confederación Española de Organizaci- } \\
\text { ones Empresariales) - najwiekszehisz- } \\
\text { pańskiezrzeszenieprzedsiębiorców. (p. } \\
63)\end{array}$ & \begin{tabular}{lr}
\multicolumn{2}{l}{ Comentario } \\
necesario & para \\
entender & la \\
noción & del \\
CEOE. &
\end{tabular} \\
\hline $\begin{array}{l}\text {-Pero, ¿de qué } \\
\text { presume? } \\
\text { Dígamelo. } \\
\text {-De ser de esos } \\
\text { de la ETA. } \\
\text { (p. 141) }\end{array}$ & ETA (p. 125) & $\begin{array}{l}\text { Sin comentario. } \\
\text { Comentario no } \\
\text { necesario, ya que } \\
\text { al lector polaco le } \\
\text { es familiar la } \\
\text { denominación } \\
\text { ETA }\end{array}$ \\
\hline $\begin{array}{l}\text {-Ha tenido } \\
\text { usted suerte, } \\
\text { podía haberse } \\
\text { ido con uno del } \\
\text { GRAPO. } \\
\text {-¿Por qué he } \\
\text { tenido suerte? } \\
\text {-Porque la ETA } \\
\text { es otra cosa. Es } \\
\text { un valor más } \\
\text { sólido. } \\
\text { (p. 141) }\end{array}$ & $\begin{array}{l}\text { GRAPO (Grupos de Resistencia Antifa- } \\
\text { scista Primero de Octubre) - Antyfa- } \\
\text { szystowskie Grupy Oporu Pierwsze } \\
\text { Października. Skrajnie lewicowa orga- } \\
\text { nizacja hiszpańska powstała w } 1975 \\
\text { jako zbrojne ramię Komunistycznej } \\
\text { Partii Hiszpanii PCE(r) Przez władze } \\
\text { hiszpańskie uważana za najbardziej } \\
\text { niebezpieczną (po ETA) organizację } \\
\text { terrorystyczną. (p. 125) }\end{array}$ & $\begin{array}{l}\text { Comentario } \\
\text { imprescindible, } \\
\text { ya que el lector } \\
\text { polaco no cono- } \\
\text { ce el nombre de } \\
\text { la organización } \\
\text { y no entenderá } \\
\text { el humor negro } \\
\text { y absurdo que } \\
\text { produce la com- } \\
\text { paración del } \\
\text { detective. }\end{array}$ \\
\hline
\end{tabular}


Los datos de la tabla muestran que solo en el caso del PSUC el comentario del traductor no es necesario, así que el texto provee el contexto para la sigla "PSUC" ("votar por los comunistas"). Los otros ejemplos (aparte de la ETA) demuestran que, a pesar de cual sea el método empleado para la reproducción del nombre en el texto traducido, el lector necesita el comentario introducido en el mismo texto o en forma del comentario externo para entender la referencia extratextual. De ahí que se evidencie que, en el momento de traducir los elementos del trasfondo histórico de la época, el traductor tiende a revelar su presencia o, en el caso cuando las notas a pie de página no son de su autoría, dejar los elementos que pertenecen al ámbito de la historia local en la versión original. Conviene resaltar que los nombres de los partidos constituyen el contexto histórico de la novela y representan uno de los elementos de la crónica. No obstante, a nuestro entender los comentarios añadidos al texto no siempre cumplen las exigencias del mismo mecanismo narrativo. A nuestro juicio, se desarrolla demasiado el concepto de los GRAPO, ya que la intervención a pie de la página impide captar el humor de la comparación irónica del detective. En el texto polaco se conserva las siglas $C E O E$, en vez de reproducir el nombre de esta organización en polaco en el mismo texto que es suficiente para entender la posición que quiere conseguir Planas. En este contexto, también parece inexplicable dejar el nombre de la Esquerra Republicana de Catalunya en su versión original sin ningún comentario. Por tanto, a pesar de que la intervención de la traductora es más perceptible, llegamos a la conclusión de que la inconsecuencia en la realización de los comentarios y la persistencia en conservar las siglas españolas en el texto traducido son un efecto de la falta de reflexión sobre su función dentro del mecanismo narrativo y solo muestra el respeto hacia la realidad histórica.

\section{Conclusión}

La falta de conocimiento sobre la cultura origen e historia por parte del lector (y traductor), muchas veces impide reproducir las referencias que requiere el mecanismo del texto. Como el autor de la serie Carvalho opta por desarrollar su concepto de novela negra, construyendo para ello una red de referencias culturales en forma de la novela detectivesca ubicada en el momento histórico bien definido, consideramos que la obligación del traductor es respetar las premisas de la serie en el proceso de traduc- 
Algunos aspectos del universo carvalhiano sometidos a la traducción 61

ción. El mismo traductor es, hasta cierto punto, responsable de hacer las pertinentes referencias a la cultura que, en el caso de la serie carvalhiana, activan los elementos fundamentales del mecanismo narrativo cuyo éxito consta de la reproducción de la imagen codificado en el texto.

En este sentido, consideramos que el traductor debería reconocer la calidad literaria del texto y sus rasgos constitutivos. Al analizar la versión polaca de Los mares del Sur realizada por Maria RaczkiewiczŚledziewska, tomando como base los elementos culturales de la investigación y el motivo que proporciona el fondo histórico, llegamos a la conclusión de que la traductora, aunque respeta la autenticidad histórica, no adopta ninguna táctica traductora a la luz de la estrategia textual de la obra. A nuestro juicio, la traductora define su responsabilidad hacia la novela en forma de la transferencia textual y en muchos casos se abstiene de intervenir o interviene en el texto sin reflexión acerca de la capacidad del texto traducido para producir imágenes del texto original. Asimismo, en este artículo postulamos que la etiqueta de la novela popular que hoy en día sigue vigente en relación a la novela policiaca, no influyera en la calidad del trabajo de la editorial y del traductor, ya que el género mismo, es decir, la novela negra, todavía sigue desarrollando su concepto complejo dentro del panorama de la cultura universal.

\section{Bibliografía}

Colmeiro, José F. La novela policiaca española, Barcelona, Anthropos, 1994.Impreso.

Eco, Umberto. Lector in fabula. La cooperación interpretativa en el texto narrativo. Barcelona: Lumen, 2000. Impreso.

---. Dzieło otwarte. Warszawa: W.A.B., 2008. Impreso

---. Decir casi lo mismo. Barcelona: Debolsillo, 2009. Impreso.

Ingarden, Roman. $O$ dziele literackim: badania $z$ pogranicza ontologii, teorii jezzyka i filozofii literatury. Warszawa: PIW, 1960. Impreso.

Kozak, Jolanta. Przekład literacki jako metafora. Między logos a lexis. Warszawa: PWN, 2009. Impreso.

Newmark, Peter. Manual de traducción. Madrid: Cátedra, 1999. Impreso.

Tyras, George. Geometrías de la memoria. Conversaciones con Manuel Vázquez Montalbán. Granada: Zoelia Ediciones, 2003. Impreso. 
---. "Entre la memoria y deseo: La poética de la huida en la obra de Vázquez Montalbán”. Manuel Vázquez Montalbán: el compromiso con la memoria. Ed. José F. Colmeiro. Woodbridge: Tamesis, 2007. 105 - 116. Impreso.

Vázquez de Parga, Salvador. De la novela policiaca a la novela negra, Barcelona: Plaza \& Janes Editores, 1986. Impreso.

Vázquez Montalbán, Manuel. Morza potudniowe. traducción de Maria Raczkiewicz-Śledziewska, Warszawa: Noir sur Blanc, 2004. Impreso. ---. Los mares del Sur. Barcelona: Editorial Planeta, 2014. Impreso.

Venuti, Lawrence. The Translator's Invisibility. London, New York: Routledge, 1995. Impreso. 